DOI: $10.13140 / R G .2 .2 .32024 .62728$

6. Alqudeimat $Y$, Alenezi D, AlHajri B, Alfouzan $H$, Almokhaizeem Z, Altamimi S, Almansouri W, Alzalzalah S, Ziyab AH. Acceptance of a COVID-19 Vaccine and Its Related Determinants among the General Adult Population in Kuwait. Med Princ Pract. 2021;30(3):262-271. doi: 10.1159/ 000514636. Epub 2021 Jan 22. PMID: 33486492; PMCID: PMC8089409.

7. Al-Qerem WA, Jarab AS. COVID-19 Vaccination Acceptance and Its Associated Factors Among a Middle Eastern Population. Front Public Health.
2021 Feb 10;9:632914. doi: 10.3389/fpubh. 2021. 632914. PMID: 33643995; PMCID: PMC7902782.

8. Wang J, Jing $R$, Lai $X$, Zhang $H$, Lyu $Y$, Knoll MD, Fang H. Acceptance of COVID-19 Vaccination during the COVID-19 Pandemic in China. Vaccines (Basel). 2020 Aug 27;8(3):482. doi: 10.3390/ vaccines 8030482. PMID: 32867224; PMCID: PMC7565574

9. Bono, Suzanna Awang et al. "Factors Affecting COVID-19 Vaccine Acceptance: An International Survey among Low- and Middle-Income Countries." Vaccines vol. 9,5 515. 17 May. 2021, doi:10.3390/vaccines 9050515

\title{
KẾT QUẢ CHĂM SÓC NGƯờI BÊ̂NH TRẦM CẢM NĂNG CÓ Ý TƯởNG HÀNH VI TỰ SÁT ĐIỀU TRI NộI TRÚ VÀ MộT SỐ YẾU TỐ LIÊN QUAN
}

\section{TÓM TẮT}

Ý tưởng và hành vi tự sát là một trong những tình trang cấp cứu trong chuyên ngành tâm thần, chủ yếu gặp ở bệnh nhân trầm cảm nặng. Nhân khẩu học, tình trang bểnh, sư tuân thủ điều tri và cách thức chăm sóc là một trong những yếu tố ảnh hưởng đến kết quả điều tri nhóm bênh nhân này. Muc tiêu: Phân tích một số yếu tố liển quan đến kết quả chăm sóc người bệnh trầm cảm nặng có ý tưởng hành vi tự sát điều trị nội trú. Đối tượng và phương pháp nghiên cứu: Nghiên cứu mô tả tiến cứu trên 103 bệnh nhân được chẩn đoán trầm cảm nặng có ý tưởng hành vi tự sát, điều trị nội trú tại Viện Sức khỏe Tâm thần Quốc gia, Bệnh viện Bạch Mai từ tháng 12 năm 2020 đến tháng 06 năm 2021, có sử dụng thang điểm đánh giá trầm cảm BECK (BECK). Kết quả: Tỉ lệ bệnh nhân điều trì tốt chiếm $22,3 \%$, thuyên giảm nhiều $(62,1 \%)$ và thuyên giảm ít chiếm $15,5 \%$. Không có bệnh nhân không thuyên giảm và tử vong. Kết quả chăm sóc tốt hơn ở nhóm bệnh nhân có thời gian diễn biến bệnh < 1 năm tốt hơn gấp 3,63 lần nhóm $\geq 1$ năm, mức độ trầm cảm nhe tốt hơn nhóm mức độ vừa và nặng gấp 5,79 lần, bệnh nhân thỉnh thoảng có ý tưởng tự sát tốt hơn nhóm thường xuyên có ý tưởng tư sát gấp 3,86 lần, mức độ tuân thủ thuốc tốt và hố trợ từ gia đinh tốt có kết quả chăm sóc tốt hơn gấp 8,33 lần nhóm bệnh nhân ít tuân thủ và ít nhận được sự hỗ trợ từ gia đình. Là các yếu tố liên quan đến kết quả chăm sóc bệnh nhân trâm cảm nặng có ý tưởng tự sát. Kết luận: Bệnh nhân trầm cảm nặng có ý tưởng, hành vi tự sát sau khi được chăm sóc, điêu trị đều có kết quả

${ }^{1}$ Đại học Thăng Long,

2Viện Sức khỏe Tâm thần, Bệnh viện Bạch Mai

${ }^{3}$ Đại họ Y Hà Nội

Chịu trách nhiệm chính: Nguyễn Thị Bích

Email: nguyenbich1786@gmail.com

Ngày nhận bài: 20.10.2021

Ngày phản biên khoa học: 22.12.2021

Ngày duyệt bài: 29.12.2021

\section{Nguyễn Thị Bích ${ }^{1,2}$, Phạm Thị Thu Hiền², Vương Thị Được $\mathrm{c}^{2,3}$, Vũ Thy Cầm²}

ổn định và thuyên giảm bệnh. Thời gian diễn biến bệnh, mức độ nặng của trầm cảm, mức độ ý tưởng tự sát, mức độ tuẩn thủ thuốc và hỗ trợ từ gia đình là những yếu tố liên quan đến kết quả chăm sóc bệnh nhân trâm cảm nặng có ý tưởng tự sát.

Tư khóa: trâm cảm nặng, ý tưởng tự sát.

\section{SUMMARY \\ SOME FACTORS RELATED TO OUTCOMES OF THE TREATMENT OF SERIOUS DEPRESSIVE PATIENTS WITH SUICIDAL IDEATION AND BEHAVIOR}

Suicidal ideation and behavior is one of the most common psychiatric emergencies, mainly seen in patients with serious depression. Demographic, medical, and cagiver factors that related to outcomes of the treatment of serious depressive patients with suicidal ideation and behavior. Objectives: Describe some factors related to outcomes of the treatment of serious depressive inpatients with suicidal ideation and behavior. Methods: A prospective descriptive study on 103 patients diagnosed with serious depression with suicidal ideation, treatment at the National Institute of Mental Health, Bach Mai Hospital from December 2020 to June 2021, using the BECK depression rating scale (BECK). Results: The rate of patients with good treatment accounted for $22.3 \%$, with much remission (62.1\%) and little remission accounted for $15.5 \%$. Duration of illness, severity of depression, severity of suicidal ideation, medication adherence, and family support are factors associated with the outcomes of patients with serious depression with suicidal ideation and behavior. Conclusion: All treated patients are in remission. Research shows that many factors are involved in the treatment of patients with serious depression who have suicidal ideation.

Keywords: Serious depression, suicidal ideation.

I. ĐẶT VẤN ĐỀ

Tự sát là một vấn đề sức khỏe cộng đồng 
toàn cầu với khoảng 800.000 người chết do tự sát năm 2014 và 20 triệu người tự sát không thành mỗi năm, được xếp hạng trong mười nguyên nhân chính gây tử vong trên toàn cầu và là nguyên nhân gây tử vong hàng đầu ở lứa tuổi thanh thiếu niên tại nhiều quốc gia $[1,2]$. Tại Việt Nam, theo Bệnh viện Tâm thần Trung Ương I, tỷ lệ tự sát năm 2015 là 5,87 trên 100000 dân [3]. Tự sát là một trong những cấp cứu của chuyên khoa và thường do nhiều nguyên nhân khác nhau liên quan đến bệnh lý tâm thần. Nguyên nhân dẫn đến tự sát trong rối loạn trầm cảm do người bệnh bi quan chán nản, tự ti, tự buộc tội, tự cho mình hèn kém không còn giá trị.

Chăm sóc người bệnh trầm cảm có ý tưởng hành vi tự sát là một trong những nhiệm vụ khó khăn nhất đối với điều dưỡng tại chuyên khoa Tâm thần. Người điều dưỡng phải có kỹ năng vận dụng linh hoạt 12 nhiệm vụ trong chăm sóc toàn diện người bệnh, đảm bảo an toàn cho người bệnh và những người xung quanh. Nhằm nâng cao năng lực chuyên môn, các điều dưỡng chuyên ngành Tâm thần cần được đào tạo bài bản về cách nhận định, theo dõi và đánh giá ý tưởng hành vi tự sát. Từ đó đưa ra các can thiệp kịp thời và chính xác nhằm đảm bảo an toàn cho người bệnh.

Hiện nay, trên thế giới có nhiều tài liệu về chăm sóc người bệnh trầm cảm có ý tưởng hành vi tự sát. Tuy nhiên ở Việt Nam chưa có nhiều công trình nghiên cứu về các yếu tố liên quan đến kết quả chăm sóc ở đối tượng này, vì vậy chúng tôi thực hiện đề tài "Kêt quả chăm sóc, điều trị người bệnh rối loạn trầm cảm nặng có ý tưởng hành vi tự sát tại Viện sức khỏe Tâm thần - Bênh viên Bach Mai năm 2020 - 2021"với mục tiêu sau: Phân tích kêt quả chăm sóc người bệnh trầm cảm nặng có ý tưởng, hành vi tự sát và một số yếu tố liên quan đến kêt quả chăm sóc người bệnh.

\section{II. ĐỐI TƯợNG VÀ PHƯƠNG PHÁP NGHIÊN CỨU}

1. Đối tượng. 103 bệnh nhân đủ tiêu chuẩn chẩn đoán xác định rối loạn trầm cảm nặng theo ICD-10[4], có ý tưởng hành vi tự sát điểu trị nội trú tại Viện sức khỏe Tâm thần - Bv Bạch Mai.

2. Phương pháp: Thiết kế nghiển cứu mô tả tiến cứu.

Sử dụng Thang đánh giá mức độ trầm cảm Beck đánh giá mức độ trầm cảm.

Các yếu tố nhân khẩu học, tiền sử bệnh và tình trạng bệnh nhân được khai thác theo mẫu bệnh án được thiết kế.

2.1. Phương pháp thu thập thông tin.
Người chăm sóc và bệnh nhân được phỏng vấn và khám bởi nghiên cứu viên là điều dưỡng chuyên khoa Tâm thần theo bệnh án mẫu, thu thập số liệu tại 3 thời điểm vào viện, sau vào viện 1 tuần và trước khi ra viện. Thời gian thu thập từ tháng 12 năm 2020 đến tháng 6 năm 2021.

3. Xử lý số liệu. Số liệu được thu thập và xử lý trên phần mềm thống kề SPSS 20.0.

4. Đạo đức nghiên cứu. Chúng tôi thông báo mục đích nghiên cứu với gia đình bệnh nhân và chỉ đưa vào danh sách nghiên cứu khi được sự đồng ý của họ. Tất cả các thông tin cá nhẩn và bệnh tật được giữ bí mật. Nghiên cứu không can thiệp vào quá trình điều trị của bệnh nhân.

\section{KẾT QUẢ NGHIÊN CỨU}

1. Đặc điểm lâm sàng chung bệnh nhân trâm cảm nặng có ý tưởng hành vi tự sát

Bảng 1. Đặc điểm lầm sàng chung bệnh nhân trầm cảm nặng có ý tưởng hành vi tự sát

\begin{tabular}{|c|c|c|c|c|}
\hline $\begin{array}{l}\text { Đăcc } \\
\text { điểm }\end{array}$ & & 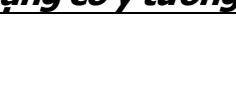 & $\mathbf{n}$ & $\%$ \\
\hline \multirow{16}{*}{$\begin{array}{l}\text { Nhân } \\
\text { khẩu } \\
\text { học }\end{array}$} & \multirow{2}{*}{ Tuổi } & Trung bình & $\begin{array}{c}42.20 \pm \\
16.92\end{array}$ & \\
\hline & & Biên độ & $14-76$ & \\
\hline & \multirow{2}{*}{ Giới } & Nam & 37 & 35.9 \\
\hline & & Nũ̃ & 66 & 64.1 \\
\hline & \multirow{5}{*}{ Học vấn } & Không đi học & 1 & 1.0 \\
\hline & & Cấp 1 & 8 & 7.8 \\
\hline & & Cấp 2 & 26 & 25.2 \\
\hline & & Cấp 3 & 19 & 18.4 \\
\hline & & $\begin{array}{c}\text { Đại học và sau } \\
\text { đai hoc }\end{array}$ & 49 & 47.6 \\
\hline & \multirow{4}{*}{$\begin{array}{l}\text { Tình trang } \\
\text { sống }\end{array}$} & Độc thân & 23 & 22.3 \\
\hline & & Có gia đình & 68 & 66.0 \\
\hline & & Ly hôn/Góa & 12 & 11.7 \\
\hline & & Tống & 103 & 100 \\
\hline & \multirow{3}{*}{$\begin{array}{l}\text { Nơi sinh } \\
\text { sống }\end{array}$} & Nông thôn & 55 & 53.4 \\
\hline & & Thành thị & 45 & 43.7 \\
\hline & & Vùng núi & 3 & 2.9 \\
\hline \multirow{12}{*}{$\begin{array}{l}\text { Lâm } \\
\text { sàng }\end{array}$} & \multirow{3}{*}{$\begin{array}{l}\text { Số năm } \\
\text { diễn biến } \\
\text { bệnh }\end{array}$} & $<1$ năm & 38 & 36.8 \\
\hline & & $1-2$ năm & 17 & 16.5 \\
\hline & & >2 năm & 48 & 46.5 \\
\hline & \multirow{2}{*}{ Loạn thân } & Hoang tưởng & 34 & 33.0 \\
\hline & & Ao giác & 6 & 5.8 \\
\hline & \multirow{3}{*}{$\begin{array}{c}\text { Triệu } \\
\text { chứng } \\
\text { chính trầm } \\
\text { cảm }\end{array}$} & Khí sắc giảm & 101 & 98.1 \\
\hline & & $\begin{array}{l}\text { Mất quan tâm } \\
\text { thích thú }\end{array}$ & 98 & 95.1 \\
\hline & & $\begin{array}{l}\text { Mệt mỏi, giảm } \\
\text { năng lượng }\end{array}$ & 102 & 99.0 \\
\hline & \multirow{4}{*}{$\begin{array}{c}\text { Cách thức } \\
\text { thực hiện } \\
\text { hành vi tự } \\
\text { sát }\end{array}$} & Thuốc & 20 & 55.6 \\
\hline & & Thắt cổ & 5 & 13.9 \\
\hline & & Dùng dao & 6 & 16.7 \\
\hline & & Khác & 5 & 13.9 \\
\hline
\end{tabular}


Nhận xét: Tỷ lệ nữ giới chiếm ưu thế hơn nam giới $(64,1 \%$ so với 35,9\%), với độ tuổi trung bình là 42,2 tuổi, đại đa số đã lập gia đình $(66,0 \%)$. Có 47,6\% bệnh nhân có trình độ đại học và sau đại học. Tỉ lệ bệnh nhân ở nông thồn và thành thị không quá khác biệt ( $53,4 \%$ và $43,7 \%)$.

Đa phần bệnh nhân diễn biến bệnh trên 2 năm (46,5\%). Tỉ lệ bệnh nhân có loạn thần là 33.0\%. Các triệu chứng chính có mặt ở hầu hết các bênh nhân nghiên cứu. Trong số 36 bệnh nhân có hành vi tự sát, dùng thuốc tự sát chiếm tỉ lệ cao $(55.6 \%)$, ngoài ra còn thắt cổ, dùng dao tự sát.

2. Đặc điểm kết quả điêu trị
Bảng 2. Phân loại kêt quả điều tri

\begin{tabular}{|c|c|c|}
\hline Kết quả điêuu trị & $\mathbf{n}$ & $\mathbf{\%}$ \\
\hline Tốt & 23 & 22.3 \\
\hline Thuyên giảm nhiêu & 64 & 62.1 \\
\hline Thuyên giảm ít & 16 & 15.5 \\
\hline Không thuyên giảm & 0 & 0 \\
\hline Tứ vong & 0 & 0 \\
\hline Tống & $\mathbf{1 0 3}$ & $\mathbf{1 0 0}$ \\
\hline
\end{tabular}

Nhận xét: Tỉ lệ bênh nhân điêu trị tốt chiếm $22,3 \%$. Chiếm chủ yểu trong nhóm bệnh nhân nghiên cứu có kết quả điều trị thuyên giảm nhiều $(62,1 \%)$. Số bệnh nhân thuyên giảm ít chiếm 15,5\%. Không có bệnh nhân không thuyên giảm và tử vong trong quá trình điều trị.

3. Mối liên quan giữa thời gian diễn biến bệnh và kết quả chăm sóc

Bảng 3. Môí liên quan giữa thời gian diển biến bệnh và kêt quả chăm sóc

\begin{tabular}{|c|c|c|c|c|c|c|}
\hline \multirow{3}{*}{ Thời gian } & \multicolumn{4}{|c|}{ Kết quả chăm sóc } & \multirow{3}{*}{$\begin{array}{c}\text { OR } \\
\text { CI } 95 \%\end{array}$} & \multirow{3}{*}{ p } \\
\hline & \multicolumn{2}{|c|}{ Tốt } & \multicolumn{2}{|c|}{ Thuyên giảm } & & \\
\hline & SL & $\%$ & $\mathbf{S L}$ & $\%$ & & \\
\hline$<1$ năm & 14 & 36,8 & 24 & 63,2 & 3,63 & $0 \cap 07$ \\
\hline$\geq 1$ năm & 9 & 13,8 & 56 & 86,2 & $(1,38-9,52)$ & 0,007 \\
\hline
\end{tabular}

Nhận xét: Bênh nhân có thời gian diễn biến bênh dưới 1 năm có kết quả chăm sóc tồt hơn nhóm $\geq 1$ năm 3,63 lần. Kết quả này có ý nghĩa thống kê với $p=0,007$

4. Mối liên quan giữa cường độ ý tưởng tự sát và kết quả chăm sóc

Bảng 4. Mối liên quan giữa cường độ ý tưởng tự sát và kết quả chăm sóc

\begin{tabular}{|c|c|c|c|c|c|c|}
\hline \multirow{3}{*}{ Cường độ trong ngày } & \multicolumn{4}{|c|}{ Kết quả chăm sóc } & \multirow{3}{*}{$\begin{array}{c}\text { OR } \\
\text { CI } 95 \%\end{array}$} & \multirow{3}{*}{$\mathbf{p}$} \\
\hline & \multicolumn{2}{|c|}{ Tốt } & \multicolumn{2}{|c|}{ Thuyên giảm } & & \\
\hline & $\mathbf{S L}$ & $\%$ & SL & $\%$ & & \\
\hline Hiếm khi, thinh thoảng & 14 & 37,8 & 23 & 62,2 & & 0.005 \\
\hline Thường xuyên, luôn luồn & 9 & 13,6 & 57 & 86,4 & $(1,47-10,14)$ & 0,000 \\
\hline
\end{tabular}

Nhận xét: Những bệnh nhân có cường độ ý tưởng tự sát thấp hơn (hiếm khi, thỉnh thoảng) có kết quả chăm sóc điêuu trị tốt hơn nhóm có cường độ ý tưởng tự sát cao (thường xuyên, luôn luôn) gấp 3,86 lần. Kết quả này có ý nghĩa thống kê với $p=0,005<0,05$

5. Mối liên quan giữa mức độ trâm cảm theo thang BECK và kết quả chăm sóc điêu trị

Bảng 5. Mối liên quan giữa mức độ trầm cảm theo thang BECK và kết quả chăm sóc điều trị

\begin{tabular}{|c|c|c|c|c|c|c|}
\hline \multirow{3}{*}{ Mức độ } & \multicolumn{4}{|c|}{ Kết quả chăm sóc } & \multirow{3}{*}{$\begin{array}{c}\text { OR } \\
\text { CI } 95 \%\end{array}$} & \multirow{3}{*}{$\mathbf{p}$} \\
\hline & \multicolumn{2}{|c|}{ Tốt } & \multicolumn{2}{|c|}{ Thuyên giảm } & & \\
\hline & $\mathbf{S L}$ & $\%$ & $\mathbf{S L}$ & $\%$ & & \\
\hline Nhe & 9 & 52,9 & 8 & 47,1 & 5,79 & רחת \\
\hline Vừa, nặng & 14 & 16,3 & 72 & 83,7 & $(1,90-17,58)$ & 0,002 \\
\hline
\end{tabular}

Nhận xét: Bệnh nhân có mức độ trầm cảm nhe theo thang Beck có kết quả chăm sóc tốt hơn nhóm mức độ vừa và nặng gấp 5,79 lî̀n. Kết quả có ý nghĩa thống kê với $p=0,002<0,05$

6. Mối liển quan giữa điêuu dưỡng làm tâm lý cho bệnh nhân và kết quả chăm sóc

Bảng 6. Môi liên quan giữa điều dưỡng làm tâm lý cho bệnh nhân và kêt quả chăm sóc

\begin{tabular}{|c|c|c|c|c|c|c|}
\hline \multirow{3}{*}{ Số lần } & \multicolumn{4}{|c|}{ Kết quả chăm sóc } & \multirow{3}{*}{$\begin{array}{c}\text { OR } \\
\text { CI } 95 \%\end{array}$} & \multirow{3}{*}{$\mathbf{p}$} \\
\hline & \multicolumn{2}{|c|}{ Tốt } & \multicolumn{2}{|c|}{ Thuyên giảm } & & \\
\hline & $\mathbf{S L}$ & $\%$ & SL & $\%$ & & \\
\hline$<2$ lần & 0 & 0 & 4 & 100 & - & 0573 \\
\hline$\geq 2$ lần & 23 & 23,2 & 76 & 76,8 & - & $0,5 / 3$ \\
\hline
\end{tabular}

Nhận xét: Việc điều dưỡng làm tâm lý cho bệnh nhân $\geq 2$ lần có kết quả chăm sóc tốt hơn nhóm bệnh nhân không được làm tâm lý. Tuy nhiên kết quả không có ý nghĩa thống kê $(p=0,573)$

7. Mối liên quan giữa sự hố trợ từ gia đình và kêt quả chăm sóc

Bảng 7. Môi liên quan giữúa sự hố trợ từ gia đỉnh và kêt quả chăm sóc 


\begin{tabular}{|c|c|c|c|c|c|c|}
\hline \multirow{3}{*}{ Hỗ trợ từ gia đình } & \multicolumn{4}{|c|}{ Kết quả chăm sóc } & \multirow{3}{*}{$\begin{array}{c}\text { OR } \\
\text { CI 95\% }\end{array}$} & \multirow{3}{*}{$\mathbf{p}$} \\
\hline & \multicolumn{2}{|c|}{ Tốt } & \multicolumn{2}{|c|}{ Thuyên giảm } & & \\
\hline & SL & $\%$ & SL & $\%$ & & \\
\hline Không, một phần & 1 & $\begin{array}{r}4,3 \\
275\end{array}$ & 22 & 95,7 & 8,33 & 0,019 \\
\hline Tốt & 22 & 27,5 & 58 & 72,5 & $(0,06-0,6,4)$ & 0,019 \\
\hline
\end{tabular}

Nhân xét: Nhóm bênh nhân có sự hồ trợ tốt từ phía gia đình có kết quả điều tri tốt hơn gấp 8,33 lần nhóm bệnh nhân không/một phần nhận được sự hỗ trợ từ gia đình. Kết quả có ý nghĩa thống kê với $p=0,019$.

8. Mối liên quan giữa đảm bảo môi trường an toàn cho bệnh nhân và kết quả chăm sóc Bảng 8. Mối liên quan giứa đảm bảo mối trường an toàn cho bệnh nhân và kêt quả chăm sóc

\begin{tabular}{|c|c|c|c|c|c|c|}
\hline \multirow{2}{*}{$\begin{array}{l}\text { Đảm bảo môi } \\
\text { trường an toàn }\end{array}$} & \multicolumn{4}{|c|}{ Kết quả chăm sóc } & \multirow{2}{*}{$\begin{array}{c}\text { OR } \\
\text { CI } 95 \%\end{array}$} & \multirow[b]{2}{*}{ p } \\
\hline & \multicolumn{2}{|c|}{ Tốt } & \multicolumn{2}{|c|}{ Thuyên giảm } & & \\
\hline Không & $\frac{S L}{4}$ & $\begin{array}{c}\% \\
44,4\end{array}$ & $\frac{\mathrm{SL}}{5}$ & $\begin{array}{c}\% \\
55,6\end{array}$ & 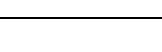 & \\
\hline Có & 19 & 20,2 & 75 & 79,8 & - & 0,110 \\
\hline
\end{tabular}

Nhận xét: Việc đảm bảo môi trường an toàn cho bệnh nhân không có mối liên quan với kết quả chăm sóc tốt của bệnh nhân $(p=0,11)$

\section{BÀN LUÂN}

Các đặc điểm về nhân khẩu học, giới tính, trình độ học vấn và nơi sinh sống tương đồng với kết quả nhiều nghiên cứu tại Việt Nam về trầm cảm [5]. Đa phần bệnh nhân diễn biến bệnh trên 2 năm $(46,5 \%)$, các triệu chứng chính có mặt ở hầu hết các bệnh nhân nghiên cứu, với tỉ lệ bệnh nhân có triệu chứng loạn thần là $33.0 \%$. Điều này phù hợp với nhiều nghiên cứu khác, như Van G.A khi tìm hiểu mối liên quan giữa ý định tự sát với mức độ nặng của trầm cảm. Tác giả cho rằng trầm cảm nặng có tất cả triệu chứng, trong đó, triệu chứng thúc đẩy mãnh liệt ý định tự sát là ý nghĩ bi quan và ý tưởng tự buộc tội [6]. Trong số 36 bệnh nhân có hành vi tự sát, dùng thuốc tự sát chiếm tỉ lệ cao (55.6\%), ngoài ra còn thắt cổ, dùng dao tự sát. Kết quả này phù hợp với nghiên cứu của Bùi Quang Huy (2013) cho thây tỉ lệ tự sát bằng thuốc ở bệnh nhân trầm cảm nặng có hành vi tự sát là $6 \dot{4}, 8 \%[7]$. Kết quả của chúng tôi thấp hơn với nghiên cứu của Nguyễn Hữu Kỳ (1996) với kết quả 87,6\% bệnh nhân dùng biện pháp ngộ độc thuốc [8].

Nghiên cứu cho thấy bệnh nhân có thời gian diễn biến bệnh dưới 1 năm có kết quả chăm sóc tốt hơn nhóm $\geq 1$ năm 3,63 lần, bệnh nhân có cường độ ý tưởng tự sát thấp hơn (hiếm khi, thỉnh thoảng) có kết quả chăm sóc điều trị tốt hơn nhóm có cường độ ý tưởng tự sát cao (thường xuyên, luôn luôn) gấp 3,86 lần. Bệnh nhân có mức độ trầm cảm nhẹ theo thang Beck có kết quả chăm sóc tốt hơn nhóm mức độ vừa và nặng gấp 5,79 lần. Kết quả này tương đồng với nghiên cứu của Dương Duy Đặng cho thấy một số đặc điểm bệnh lý trầm cảm là yếu tố tiên lượng cho khả năng tiên lượng điêu trị bệnh nhân [9].

Nghiên cứu cho thấy trong quá trình chăm sóc, bệnh nhân có sự hổ trợ tốt từ phía gia đình có kết quả điều trị tốt hơn gấp 8,33 lần nhóm bệnh nhân không/một phần nhận được sự hỗ trợ từ gia đình. Điều này không chỉ thể hiện ở quá trình chăm sóc bệnh nhân trầm cảm mà còn ở nhiều bệnh lý tâm thần khác như lo âu, tâm thần phân liệt, ám ảnh...

Tuy nhiên, theo kết quả nghiên cứu, chúng tôi chưa thây được mối liên quan giữa việc điều dưỡng làm tâm lý cho bệnh nhân và việc đảm bảo môi trường an toàn cho bệnh nhân với kết quả chăm sóc. Để làm rõ liệu có mối liên hệ này hay không cần thực hiện thêm các nghiên cứu với cõ̃ mẫu lớn hơn và phân tích các khía cạnh sâu hơn của quá tình chăm sóc.

\section{KẾT LUÂN}

Tỉ lệ bệnh nhân điều trị tốt chiếm 22,3\%. Chiếm chủ yếu trong nhóm bệnh nhân nghiên cứu có kết quả điều trị thuyên giảm nhiều $(62,1 \%)$. Số bệnh nhân thuyên giảm ít chiếm 15,5\%. Không có bệnh nhân không thuyên giảm và tử vong trong quá trình điều trị.

Thời gian diền biến bệnh, mức độ nặng của trầm cảm, mức độ ý tưởng tự sát, mức độ tuân thủ thuốc và hỗ trợ từ gia đình là các yếu tố liên quan đến chăm sóc bệnh nhân trầm cảm nặng có ý tưởng tự sát. Trong quá trình chăm sóc, việc điêuu dưỡng làm tâm lý cho bệnh nhân và đảm bảo môi trường an toàn cho bệnh nhân có ý nghĩa nhất định nhưng không phải yếu tố liên quan đến kết quả chăm sóc bệnh nhân.

Một số kiến nghị của nhóm nghiên cứu: cần có thêm nhiều nghiên cứu để làm rõ đặc điểm triệu chứng tự sát với cõ̃ mẫu lớn hơn. Đồng thời 
đưa ra những hướng dẫn với bác sĩ điều tri, điều dưỡng và người nhà chăm sóc bệnh nhân để nâng cao hiệu quả điều trị bệnh nhân trầm cảm nặng có ý tưởng hành vi tự sát.

\section{TÀI LIẸU THAM KHẢO}

1. Tổ chức y tế thế giới (2020) Preventing suicide: A global imperative.

2. Bachmann S. (2018). Epidemiology of Suicide and the Psychiatric Perspective. Int J Environ Res Public Health, 15(7).

3. Sức khóe tâm thân ở Việt Nam. $<$ https://www.who.int/vietnam/vi/healthtopics/mental-health>, accessed: 18/10/2020.

4.Tố chức y tế thế giới (1992). "Phân loại bệnh quốc tế lân thứ 10 về các rối loạn tâm thần và hành vi".

5. Bùi Quang Huy, Cao Tiến Đức (2004). Nghiên cứu một số đặc điểm dịch tễ và lâm sàng ở BN tâm thần có hành vi tự sát. Tạp chí Y - Dược học quân sự. 2004, số 2, tr.92-96.

6. Van Gastel A, Schotte $C_{\text {, Maes }} \mathbf{M}$. The prediction of suicidal intent in depressed patients. Acta Psychiatr Scand. 1997, Oct, 96 (4), pp.254-259.

7. Bưi Quang Huy (2013) Nghiên cứu về hành vi tự sát trên bệnh nhân rối loạn trầm cảm nặng. Tạp chí y học quân đội số 4, 2013.

8. Nguyến Hữu Kỳ (1996). Nghiên cứu sự liên quan giữa yếu tố ngoại lai, nhân tố tâm lý và nhân tố bệnh tâm thân ở những người toan tự sát. Luận án Tiến sỹ $Y$ học. Trường Đai hoc $Y$ Hà Nôi.

9. Dương Duy Đăng (2010) Đánh giá ý tưởng và hành vi tự sát trên người bệnh rối loạn trầm cảm năng. Luẩn văn chuyến khoa cấp 2 - Trường Đại học Y Hà Nội.

\section{TỔNG QUAN VỀ KẾT QUẢ PHẪU THUÂTT CẮT THÙYY TUYẾN GIÁP TRONG VI UNG THƯ TUYẾN GIÁP THỂ NHÚ}

\section{TÓM TẮT}

Mục tiêu: Tổng quan này nhằm để đánh giá kết quả sau phẫu thuâat cắt thùy giáp (tỷ lệ tử vong, tỷ lệ sống toàn bộ và tỷ lệ tái phát) và đưa ra các điều kiện để chỉ định phẫu thuất cắt thùy giáp ở bênh nhân vi ung thư tuyến giáp (UTTT) thể nhú. Phương pháp: Chúng tôi sử dung cơ sở dữ liêu PUBMED và EMBASE để đánh giá kết quả và điêu kiện chỉ định của phương pháp phẩu thuật cắt thùy giáp cho vi UTTG thể nhú. Kết quả: Có 09 nghiên cứu gồm 5345 bệnh nhân trong tổng quan này, thời gian theo dõi trung bình $64,6-134,8$ tháng. Trong các nghiên cứu này, chúng tôi không thây trường hợp tử vong nào liên quan đến UTTG sau phầu thuật cắt thùy giáp. Tỷ lệ sống không bênh theo phương pháp Kaplein-Meier của nhóm cắt thùy thấp hơn ở nhóm cắt toàn bộ tuyến giáp. Tỷ lệ tái phát tổng thể sau phẫu thuật cắt thùy giáp là 2,5 $\%$, vị trí tái sau phẫu thuật này tại thùy giáp còn lại là $75,3 \%$, tai giường tuyến giáp là $1,5 \%$ và di căn hach cố là $23,2 \%$. Không có trường hợp di căn xa trong thời gian theo dõi. Kết luận: Cắt thùy giáp có kết quả tương tự như cắt toàn bộ tuyến giáp trong vi UTTG thể nhút tỷ lệ tử vong, thời gian sống toàn bộ, tỷ lệ tái phát). Do vậy có thể chỉ định cắt thùy giáp cho vi UTTG thể nhú với các điều kiện được thỏa mãn.

\section{SUMMARY}

\footnotetext{
${ }^{1}$ Bệnh viện đại học Y Hà Nội.

${ }^{2}$ Trường đại học Y Hà Nội.

Chịu trách nhiệm chính: Trần Thế Diệu

Email: tranthedieu2009@gmail.com

Ngày nhận bài: 25.10.2021

Ngày phản biên khoa họ: 20.12.2021

Ngày duyệt bài: 30.12.2021
}

\section{SCOPING REVIEW OF THE OUTCOMES OF THYROID LOBECTOMY IN PAPILLARY THYROID MICROCARCINOMA}

Objective: This review evaluates the outcomes after lobectomy (mortality rate, overall survival rate, and recurrence rates) and give the standards of the indication for lobectomy in patients with papillary thyroid microcarcinoma. Methods: We used the PUBMED and EMBASE databases to evaluate the results and indications of lobectomy for papillary thyroid carcinoma. Results: There were 09 studies with 5345 patients in this overview, the average follow-up time was 64.6 - 134.8 months. In these studies, we did not see any deaths related to thyroid carcinoma after lobectomy. Kaplein-Meier disease-free survival was lower in lobectomy group than total thyroidectomy group. The overall recurrence rate after lobectomy is $2.5 \%$, the recurrence site after this surgery is $75.3 \%$ in the remaining thyroid lobe, $1.5 \%$ at the thyroid bed, and cervical lymph node metastasis is $23.2 \%$. There were no cases of distant metastases during the follow-up period. Conclusion: Lobectomy has similar results as total thyroidectomy in papillary thyroid carcinoma (mortality rate, overall survival, recurrence rate). Therefore, lobectomy may be indicated for papillary thyroid microcarcinoma, provided the standards conditions are satisfied.

\section{I. ĐẶT VẤN ĐỀ}

Vi UTTG thể nhú theo định nghĩa của Tổ chức $Y$ tế Thế giới (WHO), là các ung thư tuyến giáp thể nhú có đường kính tối đa $1 \mathrm{~cm}$. Tỷ lệ mắc vi ung thư biểu mô tuyến giáp thể nhú ngày càng tăng lên, năm 2014 hơn 50\% các trường hợp UTTG mắc mới là vi UTTG thể nhúi1-3. Tuy nhiên, 